\title{
Gene Expression Profile and Response to Maize Kernels by Aspergillus flavus
}

\author{
Brittiney N. Reese, Gary A. Payne, Dahlia M. Nielsen, and Charles P. Woloshuk
}

First and fourth authors: Department of Botany and Plant Pathology, Purdue University, West Lafayette, IN 47907; second author: Department of Plant Pathology, and third author: Department of Genetics, North Carolina State University, Raleigh 27695. Accepted for publication 9 February 2011.

\section{ABSTRACT}

Reese, B. N., Payne, G. A., Nielsen, D. M., and Woloshuk, C. P. 2011. Gene expression profile and response to maize kernels by Aspergillus flavus. Phytopathology 101:797-804.

Aspergillus flavus causes an ear rot of maize, often resulting in the production of aflatoxin, a potent liver toxin and carcinogen that impacts the health of humans and animals. Many aspects of kernel infection and aflatoxin biosynthesis have been studied but the precise effects of the kernel environment on A. flavus are poorly understood. The goal of this research was to study the fungal response to the kernel environment during colonization. Gene transcription in A. flavus was analyzed by microarrays after growth on kernels of the four developmental stages: blister (R2), milk (R3), dough (R4), and dent (R5). Five days after inoculation, total RNA was isolated from kernels and hybridized to
Affymetrix Gene Chip arrays containing probes representing 12,834 A. flavus genes. Statistical comparisons of the expression profile data revealed significant differences that included unique sets of upregulated genes in each kernel stage and six patterns of expression over the four stages. Among the genes expressed in colonized dent kernels were a phytase gene and six putative genes involved in zinc acquisition. Disruption of the phytase gene phyl resulted in reduced growth on medium containing phytate as the sole source of phosphate. Furthermore, growth of the mutant ( $\Delta p h y 1)$ was $20 \%$ of the wild-type strain when wound inoculated into maize ears. In contrast, no difference was detected in the amount of aflatoxin produced relative to fungal growth, indicating that phyl does not affect aflatoxin production. The study revealed the genome-wide effects of immature maize kernels on A. flavus and suggest that phytase has a role in pathogenesis.
Aspergillus flavus Link (teleomorph: Petromyces flavus B. W. Horn, I. Carbone \& G. G. Moore) causes Aspergillus ear rot in maize and infects a wide range of oil-seed crops such as peanut, tree nuts, and cottonseed $(3,37)$. Optimum environmental conditions for disease development include high temperatures and drought. When disease is established, A. flavus produces the toxic secondary metabolite aflatoxin. Among the multiple forms of aflatoxin, aflatoxin B1 (AFB1) is the predominant one produced. When ingested, AFB1 often causes liver necrosis, acute toxicity, cancer, or even mortality (26). Because of the risk of cancer in humans, the sale of aflatoxin-contaminated grain is restricted in the United States and world markets. It is estimated that, currently, over 55 million people are exposed to aflatoxin at unhealthy levels (19).

The biosynthetic pathway for aflatoxin is well characterized, as is the 70-kb cluster of genes responsible for its production and regulation (40). Furthermore, in vitro studies have provided extensive information about the influence that factors such as temperature, $\mathrm{pH}$, and carbon source have over aflatoxin production $(5,15,29,31)$. Still lacking is an understanding of how the environment within the living kernel impacts the pathogen. Such studies have been difficult because, during infection of the host, the fungus encounters kernels in different stages of development.

When A. flavus infects a maize kernel, it encounters a nutrient environment that is dependent on the stage of kernel development. Maturation of the maize kernel consists of a series of stages classified as R1 to R6 (28). The R2 (blister) kernel is the first

Corresponding author: C. P. Woloshuk; E-mail address: woloshuk@purdue.edu

* The $\boldsymbol{e}$-Xtra logo stands for "electronic extra" and indicates that the online version contains one supplementary table.

doi:10.1094/PHYTO-09-10-0261

(c) 2011 The American Phytopathological Society distinctive kernel stage, with a small embryo and a differentiated aleurone layer (14). Ingle et al. (14) found that the clear fluid of blister kernels is rich in free amino acids, and that the levels of soluble nitrogen, amino acids, and nucleotides peaked at 28 days after pollination (DAP), when cell division in the endosperm is complete. In this stage, programmed cell death of endosperm cells begins in the central and crown region $(38,39)$ and progresses toward the base of the kernel (39), while the embryo actively accumulates proteins and lipids. Based on these observations, we hypothesized that, as A. flavus infects kernels, the nutrient status in each of the developmental stages will impact gene expression in the fungus.

In this study, we examined the response of A. flavus during colonization of four developmental stages (R2 to R5) of maize. Recent sequencing of the A. flavus genome (25) and the subsequent availability of an Affymetrix Gene Chip, which contains probes for 12,834 genes, made it possible to analyze wholegenome expression profiles. The analysis revealed sets of upregulated genes that reflect the expected nutrient condition within each developmental stage. We also functionally characterized a putative phytase gene, phyl, which was uniquely upregulated during growth on dent stage (R5) kernels. Characterization of a phytase mutant, $\Delta p h y l$, indicated that phytase in A. flavus may be important during pathogenesis.

\section{MATERIALS AND METHODS}

Fungal strains and culture conditions. Strains of A. flavus (NRRL3357 and AFC-1) used in this study were stored in 20\% glycerol at $-80^{\circ} \mathrm{C}$. AFC-1 was derived from NRRL3357 and contains mutations in pyrG and $\arg D$ (11). Fungi were maintained on potato dextrose agar medium (PDA) (Becton-Dickinson, Sparks, MD) and, when necessary, $7.5 \mathrm{mM}$ uracil and $1.5 \mathrm{mM}$ arginine were added. Other media used included potato dextrose 
broth with $7.5 \mathrm{mM}$ uracil (PDBU); protoplast recovery medium (Czapek-Dox Broth [Becton-Dickinson] containing $0.4 \mathrm{M}$ $\left[\mathrm{NH}_{4}\right]_{2} \mathrm{SO}_{4}$ and $1 \%$ agar) supplemented with $7.5 \mathrm{mM}$ uracil when necessary; and phytate medium, consisting of $30 \mathrm{~g}$ of sucrose, $2 \mathrm{~g}$ of $\mathrm{NaNO}_{3}, 0.5 \mathrm{~g}$ of $\mathrm{MgSO}_{4}, 0.01 \mathrm{~g}$ of $\mathrm{FeSO}_{4}$, and $0.63 \mathrm{~g}$ of sodium phytate per liter. The sodium phytate in phytate medium was replaced with $1 \mathrm{~g}$ of $\mathrm{KH}_{2} \mathrm{PO}_{4}$ in a phosphate control medium.

Inoculation of maize kernels. For microarray studies, maize inbred B73 was grown in fields at the Agronomy Center for Research and Education (Purdue University, West Lafayette, IN). During the growing season, ears were harvested and brought to the laboratory when maturity reached developmental stages corresponding to blister (R2), milk (R3), dough (R4), and dent (R5). The kernels were carefully removed from 5 to 10 ears, combined in a beaker, surface sterilized with $5 \% \mathrm{NaClO}$, rinsed thoroughly with sterile water, wounded, and placed in sterile vials (2). Each vial contained $\approx 5 \mathrm{~g}$ of kernels, and vials were inoculated with 5,000 conidia of $A$. flavus NRRL 3357 and incubated at $28^{\circ} \mathrm{C}$. Caps on the vial remained loose to a allow oxygen uptake and each vial was shaken daily. After 4 days, the vials were flash frozen with liquid nitrogen and stored at $-80^{\circ} \mathrm{C}$ until use for RNA isolation (microarray analysis), ergosterol analysis, and aflatoxin analysis.

For pathogenicity studies, maize B73 seed were sown into inground beds within the greenhouse and plants were provided with lighting for $14 \mathrm{~h} /$ day with an average temperature of $30^{\circ} \mathrm{C}$. Plants were hand pollinated and ears were harvested at dough (R4) stage. For inoculation, ear husks were pulled back and silks were removed. For each ear, 6 to 10 rows of kernels were inoculated with a pin bar (16) (18 pins; $0.5 \mathrm{~cm}$ in depth) that was dipped into a reservoir containing a suspension of $1 \times 10^{7}$ conidia in $0.05 \%$ Triton X-100. After inoculation, the husks were replaced over the ears, secured with a rubber band, and placed in a plastic container with a moist paper towel to maintain high humidity. The containers were placed in the greenhouse and disease was assessed after 5 days. Kernels were collected for ergosterol and aflatoxin analyses. For each strain, three ears were tested, and the experiment was performed twice.

Nucleic acid isolation and quantitative reverse-transcriptase polymerase chain reaction. Bacterial plasmids were isolated with a Qiagen Miniprep DNA Purification System (Qiagen, Valencia, CA). Fungal genomic DNA was isolated as described previously (30). Total RNA was isolated and purified from three vials for each developmental stage as described by Bluhm et al. (1). For cDNA synthesis, 1 to $2 \mu \mathrm{g}$ of total RNA (0.5 to $7.0 \mu \mathrm{l})$ was treated with DNase in a reaction tube containing RNaseOut ribonuclease inhibitor (1.0 $\mu \mathrm{l}$ ) (Invitrogen, Carlsbad, CA), RNase- free water $(0$ to $6.5 \mu \mathrm{l}), 10 \times$ reaction buffer $(1.0 \mu \mathrm{l})$ (Promega Corp., Madison, WI), and DNase $(1.0 \mu \mathrm{l})$ (Promega Corp.) in a final volume of $10 \mu \mathrm{l}$. After $30 \mathrm{~min}$ of incubation at $37^{\circ} \mathrm{C}, 1 \mu \mathrm{l}$ of stop solution (Promega) was added to the tube, followed by a 10 -min incubation at $65^{\circ} \mathrm{C}$. For cDNA synthesis, a reaction mixture containing treated RNA $(10 \mu \mathrm{l}), 1 \mu \mathrm{l}$ of $500 \mathrm{ng} / \mu \mathrm{l}$ Oligo (DT) 15 Primer (Promega Corp.), $1 \mu \mathrm{l}$ of $10 \mathrm{mM}$ dNTPs (SigmaAldrich, St. Louis), and $1 \mu$ of RNase-free water was incubated for $5 \mathrm{~min}$ at $65^{\circ} \mathrm{C}$ followed by $1 \mathrm{~min}$ on ice. After addition of $1 \mu \mathrm{l}$ of RNase Out (Invitrogen), $1 \mu \mathrm{l}$ of Superscript II reverse transcriptase (Invitrogen), $4 \mu$ of $5 \times$ reaction buffer, and $1 \mu \mathrm{l}$ of $0.1 \mathrm{M}$ dithiothreitol (Invitrogen), the reaction was incubated for $60 \mathrm{~min}$ at $42^{\circ} \mathrm{C}$. Control reactions were performed without reverse transcriptase. The synthesis was stopped by incubation at $70^{\circ} \mathrm{C}$ for $10 \mathrm{~min}$, and cDNA was stored at $-80^{\circ} \mathrm{C}$. Quantitative reversetranscriptase polymerase chain reaction (qRT-PCR) analysis was by the method described by Bluhm et al. (1). Primer sets used were RT-STR (F/R), Phy1.7 (F/R), and RT-ZTF (F/R) (Table 1).

Microarray analysis. Total RNA was isolated from colonized maize kernels at each developmental stage. Each vial represented a biological replicate, and three replicates were analyzed for each treatment (developmental stage). Total RNA from each vial was processed in the Purdue University Genomics Center and hybridized to a custom A. flavus Affymetrix GeneChip (AFAVUSa520391F), which contains probes representing 12,834 A. flavus genes and 8,895 maize genes (25). Intensity values from each set of 11 perfect-match probes were imported from Affymetrix CEL files and summarized with dChip (17). The mismatch data were excluded from the analysis. JMP Genomics software (SAS Institute, Cary, NC) was used for all subsequent statistical analyses, including a Loess normalization. Data quality from each set of replicates was assured by examination with the data distribution function in the JMP Genomics software. Differential gene expression between the treatments (developmental stages) was determined by analysis of variance using a significance threshold based on a false discovery rate of 0.001 . The analysis of microarrays probed with RNA isolated from uninfected maize kernels for each developmental stage showed no significant signals from the A. flavus probes on the chip.

Fungal transformation and deletion of phy1. The phytase gene phyl (AFLA_111040) was deleted in strain AFC-1 by homologous recombination. Strain AFC-1 has mutations in $\arg G$ and pyrl, which provide selectable markers for gene disruption and for subsequent complementation experiments. A disruption vector (koPHY1) was constructed by the double-joint PCR strategy described by Yu et al. (40). Nucleotide sequences $5^{\prime}$ and

TABLE 1. Primers used throughout this study

\begin{tabular}{ll}
\hline Primer & \multicolumn{1}{c}{${\text { Sequence } 5^{\prime}-3^{\prime}}^{\prime}$} \\
\hline Phy $1.1 \mathrm{~F}$ & TTGGGGGATGGCTTTTTCTTGTCT \\
Phy1.1R & CTTTCATTAGGGCATCGGGTTCGTGGGCCGCTCTTCGCTC \\
Phy $1.2 \mathrm{~F}$ & AATCCAAACCCCTCACGCCTTGTGACGCTGATAGGCTGTGTTGG \\
Phy $1.2 \mathrm{R}$ & AGGGGATCTCCGTGCGACTTG \\
Phy $1.3 \mathrm{~F}$ & AGTTTGTGGGATTGGGGTATTCAT \\
Phy1.3R & TTCTTTCTCCTGCGGCTGCGGCTGTC \\
Phy $1.4 \mathrm{~F}$ & CTGGGACGGAGGAGAGGAAGGATG \\
Phy1.4R & CTCCATATCCCACAAGTAGCATCC \\
Phy1.5F & TCACCTCGACACTTCTTTCCATTC \\
Phy1.5R & CTTGGACACGCACTTGATGGA \\
Phy1.6F & CTGGGACGGAGGAGAGGAAGGAT \\
Phy1.6R & GCGTGGGAAGTGTATTGGCTGTAG \\
Phy $1.7 \mathrm{~F}$ & CTCCCCAGTTTCCAACCCGATGTAA \\
Phy1.7R & CCCCCTTCTGCGCTTTGTTCAC \\
ArgGF & AGGCGTGAGGGGGTTTGGATT \\
ArgGR & ACCCGGCGAGAAGCGAGTGAG \\
RT-STF & GTGCGCCTCCCAGAACATTG \\
RT-STR & CGACGGCGGCGAGATTT \\
RT-ZTF & AGCTGGCTACCCTGGATTCTGTG \\
RT-ZTR & CGCGGTATACGAGCCTGAGTTG \\
\hline
\end{tabular}


$3^{\prime}$ of phyl were amplified by PCR with primer sets Phy1.1 (F/R) and Phy1.2 (F/R) (Table 1; Fig. 1A), respectively. PCR conditions were 1 cycle of $2 \mathrm{~min}$ at $94^{\circ} \mathrm{C}$ and 34 cycles of $45 \mathrm{~s}$ at $94^{\circ} \mathrm{C}, 30 \mathrm{~s}$ at $55^{\circ} \mathrm{C}$, and $1.5 \mathrm{~min}$ at $72^{\circ} \mathrm{C}$. The entire $\arg D$ gene was amplified from A. flavus 3357 with primer set $\operatorname{ArgG}(\mathrm{F} / \mathrm{R})$ (Table 1). PCR conditions were 1 cycle of $2 \mathrm{~min}$ at $96^{\circ} \mathrm{C}$ and 34 cycles of $20 \mathrm{~s}$ at $96^{\circ} \mathrm{C}, 20 \mathrm{~s}$ at $55^{\circ} \mathrm{C}$, and $2 \mathrm{~min}$ at $72^{\circ} \mathrm{C}$. For vector construction, the three PCR products were mixed in a PCR for 10 cycles of $20 \mathrm{~s}$ at $94^{\circ} \mathrm{C}, 7 \mathrm{~min}$ at $58^{\circ} \mathrm{C}$, and $5 \mathrm{~min}$ at $72^{\circ} \mathrm{C}$. Subsequently, the entire koPHY1 construct was amplified with the nested primer set Phy1.3 (F/R) (Table 1; Fig. 1B). The PCR conditions were 1 cycle of $2 \mathrm{~min}$ at $94^{\circ} \mathrm{C}$ and 30 cycles of $10 \mathrm{~s}$ at $96^{\circ} \mathrm{C}, 30 \mathrm{~s}$ at $56.5^{\circ} \mathrm{C}$, and $7 \mathrm{~min}$ at $72^{\circ} \mathrm{C}$.

For transformation, strain AFC-1 was grown in PDBU medium for 8 to $12 \mathrm{~h}$ on a rotary shaker at $200 \mathrm{rpm}$ at $28^{\circ} \mathrm{C}$. Mycelia were collected by centrifugation in a clinical centrifuge, washed twice with sterile water, and resuspended in $30 \mathrm{ml}$ of a freshly prepared enzyme solution ( $0.14 \mathrm{~g}$ of lysing enzyme [Sigma-Aldrich], $25.5 \mathrm{ml}$ of $1.2 \mathrm{M} \mathrm{NaCl}, 3 \mathrm{ml}$ of $0.2 \mathrm{M} \mathrm{NaPO}_{4}$ [pH 5.8], $350 \mu \mathrm{l}$ of $\beta$-glucuronidase, and $0.08 \mathrm{~g}$ of bovine serum albumen), which was filter-sterilized through a $0.45-\mu \mathrm{m}$ filter. After incubation for 3 to $4 \mathrm{~h}$ at $30^{\circ} \mathrm{C}$ and shaking at $70 \mathrm{rpm}$, the digestion was centrifuged in a clinical centrifuge for $1 \mathrm{~min}$ to pellet the undigested mycelia. The supernatant, which contained protoplasts, was passed through a nylon mesh $(100 \mu \mathrm{m})$ into a $50-\mathrm{ml}$ centrifuge tube, and STC buffer (218.64 $\mathrm{g}$ of sorbitol, $10 \mathrm{ml}$ of $1 \mathrm{M}$ TrisCl [pH 7.5], and $10 \mathrm{ml}$ of $1 \mathrm{M} \mathrm{CaCl}_{2}$ in 1 liter) was added to a final volume of $50 \mathrm{ml}$. After centrifugation, the pellet containing the protoplasts was washed once with STC buffer. The protoplasts were suspended in STC buffer and the concentration was adjusted to $10^{7}$ per milliliter. For transformation, $100 \mu \mathrm{l}$ of protoplasts was mixed with 1 to $10 \mu \mathrm{g}$ of vector DNA (koPHY1) in a $1.5-\mathrm{ml}$ microcentrifuge tube. After incubation on ice for $30 \mathrm{~min}, 1 \mathrm{ml}$ of $50 \%$ polyethylene glycol was added to the tube and warmed to $37^{\circ} \mathrm{C}$ for $30 \mathrm{~s}$. The mixture was then incubated for 20 to $30 \mathrm{~min}$ at room temperature before the protoplasts were plated onto recovery media containing uracil. Transformants were screened for the deletion of phyl by PCR with the $5^{\prime}$ primer set Phy1.4 (F/R) and $3^{\prime}$ set Phy1.5 (F/R) (Table 1; Fig. 1B). The PCR conditions were 1 cycle of $2 \mathrm{~min}$ at $94^{\circ} \mathrm{C}$ and 30 cycles of $45 \mathrm{~s}$ at $94^{\circ} \mathrm{C}, 30 \mathrm{~s}$ at $56^{\circ} \mathrm{C}$, and $1.5 \mathrm{~min}$ at $72^{\circ} \mathrm{C}$.

To complement the pyrG mutation, protoplasts of the phyldeletion strain ( $\Delta$ phylpyrl) were transformed with pRG3 (36) and plated onto recovery medium lacking uracil. For comple- mentation of the phyl-deletion, protoplasts of ( co-transformed with full-length phyl and pRG3. The entire phyl gene was amplified from A. flavus 3357 with primer set Phy1.6 (F/R) (Table 1; Fig. 1A). Transformants were selected for growth on recovery medium lacking uracil and then tested for growth on phytate medium and by PCR.

Growth determination. Growth was measured by dry weight and ergosterol content. For dry-weight analysis, fungal strains were grown in liquid media for 5 days at $37^{\circ} \mathrm{C}$. The mycelia were collected on preweighed filter paper, washed with water, and placed in a drying oven at $80^{\circ} \mathrm{C}$. After drying, the net weight of the mycelium was determined. For ergosterol analysis, colonized kernels from inoculated maize ears were ground and $0.5 \mathrm{~g}$ of tissue was extracted with 2:1 chloroform/methanol (1). Ergosterol was measured by high-performance liquid chromatography as described previously (1).

Phytase assay. Quantification of phosphate released from phytic acid was used to determine phytase activity. Conidia $(n=$ 5,000 ) of each fungal strain were inoculated into PDB medium and grown for $48 \mathrm{~h}$. Mycelia were collected by centrifugation, washed with sterile water, and resuspended in $0.5 \mathrm{ml}$ of $44 \mathrm{mM}$ sodium phytate $(\mathrm{pH} 2.5)$. After an induction period of $24 \mathrm{~h}$ at $37^{\circ} \mathrm{C}$, the mixture was centrifuged and $100 \mu \mathrm{l}$ of the supernatant was mixed with $0.4 \mathrm{ml}$ of $44 \mathrm{mM}$ sodium phytate $(\mathrm{pH} \mathrm{2.5)}$ and incubated for $24 \mathrm{~h}$ at $37^{\circ} \mathrm{C}$. Free phosphate was measured by addition of $1 \mathrm{ml}$ of freshly prepared color reagent consisting of acetone/5 $\mathrm{N}$ sulfuric acid/5\% ammonium molybdate (2:1:1, $\mathrm{vol} / \mathrm{vol} / \mathrm{vol}$ ) (12). Absorbance was measured at $400 \mathrm{~nm}$, and free phosphate was determined by comparison with a standard curve based on readings of $\mathrm{KH}_{2} \mathrm{PO}_{4}$ standards.

Aflatoxin analysis. The chloroform/methanol extracts obtained for ergosterol analysis were spotted onto thin-layer chromatography (TLC) plates (K5 silica gel) (Whatman, Piscataway, NJ) for analysis of aflatoxin B1. After development in ether/methanol/ water (96:3:1), the TLC plates were digitally photographed under UV. Density values were obtained from the images with ImageJ (http://rsb.info.nih.gov/ij). Quantification was based on comparison with aflatoxin B1 standards that were included on each TLC plate.

\section{RESULTS}

Differentially expressed genes during colonization. Growth of A. flavus on the four developmental kernel stages of maize (R2

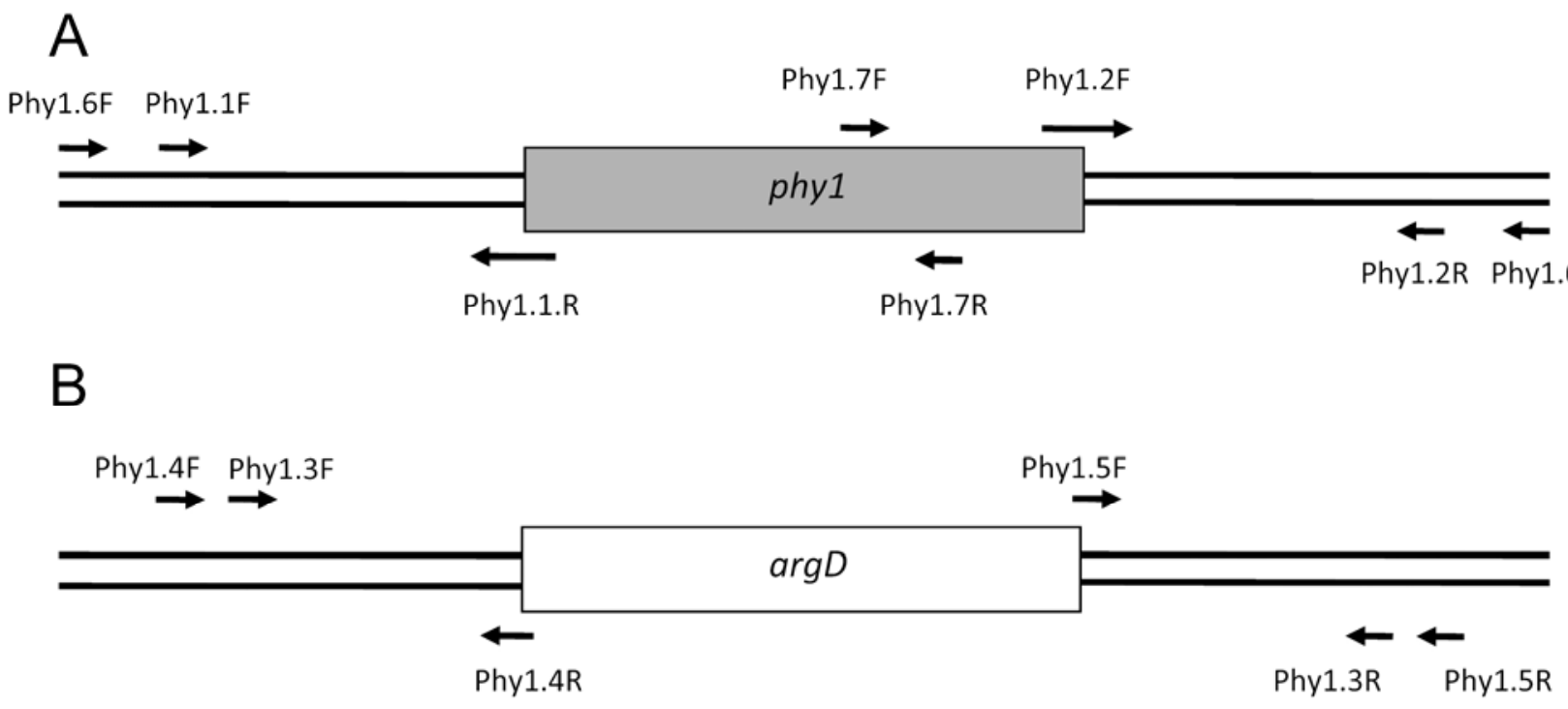

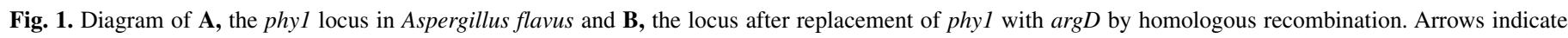
the position of various polymerase chain reaction primers used in this study. 
to R5) was similar and low levels of aflatoxin were produced in all kernel stages (Table 2). Pairwise comparisons of genes expressed by $A$. flavus during growth on the four kernel stages indicated a total of 1,441 differentially expressed genes (Table 3). The lowest number of differentially expressed genes was found in the comparisons of blister to milk $(n=154)$ and milk to dough $(n=139)$. The highest number of genes was identified in the comparisons of dough to dent $(n=772)$. Although gene annotation and ontology assignments to the A. flavus genome are limited, the products of genes identified as significant were categorized by BLAST analysis and placed into one of eight functional categories (Table 3) or into a group designated "hypothetical proteins". The results indicate that different subsets of genes are upregulated during growth on the different kernel stages. Comparisons with dent indicated more secondary metabolism genes expressed (Table 3), consisting mostly of the aflatoxin biosynthesis genes.

We next addressed how kernel developmental stage at the time of inoculation affected gene expression in A. flavus. The 1,441 significantly expressed genes identified from the six paired analyses (Table 3 ) were sorted to identify unique sets of genes, either up- or downregulated, that were associated specifically with

TABLE 2. Growth of Aspergillus flavus and aflatoxin production in colonized maize kernels $^{\mathrm{a}}$

\begin{tabular}{lll}
\hline Stage & Growth $^{\mathrm{b}}$ & Aflatoxin $^{\mathrm{c}}$ \\
\hline Blister & $125.0(11.3)$ & $0.92(0.20)^{*}$ \\
Milk & $158.7(9.4)$ & $0.44(0.03)$ \\
Dough & $143.3(10.7)$ & $0.46(0.01)$ \\
Dent & $150.0(40.5)$ & $0.31(0.07)$ \\
\hline
\end{tabular}

${ }^{a}$ Kernels from different developmental stages were removed from ears, surface sterilized, wounded, and inoculated with A. flavus. Kernels were analyzed 5 days after inoculation.

${ }^{b}$ Values are mean micrograms of ergosterol per gram of maize kernel from three replicate ears, and the values inside the parentheses are standard error.

c Values are mean micrograms of aflatoxin B1 per microgram of ergosterol per gram of maize kernel from three replicate ears, and values inside the parentheses are standard error; * indicates significant difference from other values in column. Data were analyzed by an analysis of variance with a Fisher's least significant difference test to compare means $(\alpha=0.05)$ (PROC GLM; SAS Institute 2001). the developmental stage of the kernels (Table 4). The expression of these genes was significant only in one developmental stage when compared with the other stages. Only two unique genes were expressed on the colonized milk kernels, likely reflecting similarity to blister and to dough. The putative functions of the genes unique to blister and dent are interesting because of their putative function. Seven upregulated genes in the blister stage kernels are associated with amino acid and protein metabolism. Putative functions of four of these genes involve amino acid transport and three are involved in protein synthesis. In contrast, 11 of the 12 upregulated amino acid genes in dent kernels have putative functions in protein synthesis. Also, the three downregulated genes in dent are associated with amino acid transport. Other interesting genes unique to growth on dent stage kernels were 10 downregulated genes involved in pectin metabolism and two upregulated lipase genes. In the category of putative transport genes, 6 of the 11 upregulated genes were zinc transporters and 17 of the 19 downregulated genes were putative sugar transporters.

Pattern of expression: analysis of blister (R2) and dent (R5). Ingle et al. (14) indicated that blister and dent kernels are the most diverse with respect to nutrient composition. Our analysis indicated 225 differentially expressed genes, which included 145 genes with higher expression in blister kernels (blister/dent; Table 3; Supplementary Table 1). The comparison revealed that a number of genes with putative functions involved in amino acid or protein metabolism, carbon metabolism, and transport had greater expression in colonized blister kernels than dent kernels blister/dent; Table 3; Supplementary Table 1). In colonized dent kernels, genes associated with oxidation or reduction, zinc metabolism, and secondary metabolism were more highly expressed. Expression of the 225 genes was examined across the four developmental stages to determine whether expression of each gene changed significantly from one kernel stage to the next. Through this analysis, 190 genes were assigned to one of six expression patterns (Table 5). Of the 145 genes that are upregulated in A. flavus during growth on blister kernels, 63 followed pattern BI, downregulated during growth on milk, dough, and dent kernels. A second group, comprising 46 genes, followed the pattern BIII, in which expression remained significantly high until the dent stage. Among these genes were 10 with putative

TABLE 3. Differentially expressed genes in Aspergillus flavus during colonization of the different stages of kernel development ${ }^{\mathrm{a}}$

\begin{tabular}{|c|c|c|c|c|c|c|c|}
\hline Gene & Total & Blister/milk & Milk/dough & Dough/dent & Blister/dough & Blister/dent & Milk/dent \\
\hline Total significant & 1,441 & $85 / 69$ & $102 / 37$ & $349 / 423$ & $287 / 208$ & $145 / 80$ & $318 / 255$ \\
\hline AA/protein metabolism & 57 & $4 / 12$ & $3 / 4$ & $26 / 20$ & $15 / 19$ & $8 / 4$ & $23 / 17$ \\
\hline Lipid metabolism & 30 & $0 / 6$ & $7 / 12$ & $10 / 9$ & $9 / 12$ & $6 / 5$ & $8 / 4$ \\
\hline Carbon metabolism & 83 & $8 / 12$ & $5 / 3$ & $46 / 31$ & $11 / 22$ & $14 / 1$ & $21 / 16$ \\
\hline Oxidative & 114 & $7 / 28$ & $20 / 7$ & $37 / 50$ & $44 / 29$ & $16 / 19$ & $40 / 32$ \\
\hline Transport & 103 & $5 / 7$ & $8 / 5$ & $51 / 27$ & $17 / 24$ & $19 / 13$ & $46 / 24$ \\
\hline Regulatory & 61 & $2 / 1$ & $1 / 2$ & $6 / 13$ & $7 / 4$ & $18 / 17$ & $7 / 9$ \\
\hline Secondary metabolism & 31 & $2 / 1$ & $1 / 0$ & $2 / 18$ & $3 / 1$ & $2 / 8$ & $5 / 19$ \\
\hline Nitrogen metabolism & 3 & $1 / 0$ & $0 / 1$ & $2 / 2$ & $1 / 3$ & $2 / 0$ & $1 / 2$ \\
\hline
\end{tabular}

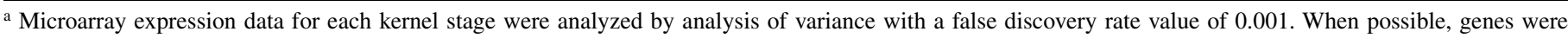
placed into one of eight functional categories. Values represent the number of genes upregulated in each developmental stage in the comparisons.

TABLE 4. Differentially expressed genes in Aspergillus flavus specific to colonization of the different kernel stages of development ${ }^{\mathrm{a}}$

\begin{tabular}{|c|c|c|c|c|c|c|c|c|}
\hline \multirow[b]{2}{*}{ Gene } & \multicolumn{2}{|c|}{ Blister } & \multicolumn{2}{|c|}{ Milk } & \multicolumn{2}{|c|}{ Dough } & \multicolumn{2}{|c|}{ Dent } \\
\hline & Up & Down & Up & Down & Up & Down & Up & Down \\
\hline Total significant & 23 & 7 & 1 & 1 & 15 & 18 & 63 & 50 \\
\hline $\mathrm{AA} /$ protein metabolism & 7 & 1 & 0 & 0 & 2 & 0 & 12 & 3 \\
\hline Lipid metabolism & 0 & 0 & 0 & 0 & 3 & 3 & 3 & 1 \\
\hline Carbon metabolism & 3 & 3 & 0 & 0 & 1 & 4 & 9 & 19 \\
\hline Transport & 1 & 0 & 0 & 0 & 4 & 3 & 11 & 19 \\
\hline
\end{tabular}

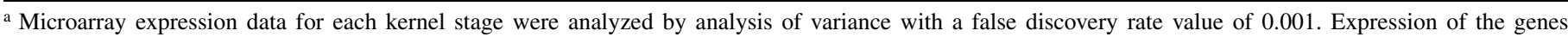
identified was significant to in all comparisons. When possible, genes were placed into one of four functional categories. 
functions in carbohydrate metabolism, 9 with putative $\mathrm{ABC} / \mathrm{MF}$ transporter functions, and 4 putative amino acid transporters.

Data from the comparison of blister and dent also revealed 80 genes more highly expressed in the dent kernels (Table 3). Expression of 58 genes was low in the blister, milk, and dough kernels, then increased significantly in dent kernels. This pattern was designated DIII (Table 5). Among this group of genes, four have putative functions in amino acid and protein metabolism, of which three are biosynthetic. Also in this group are six putative $\mathrm{ABC} / \mathrm{MF}$ transporter genes, five lipid metabolism genes, six zinc transporter genes, and eight genes involved in secondary metabolism, including three aflatoxin biosynthesis genes.

To validate the expression pattern, the expression of three genes was analyzed by qRT-PCR (Table 6). Expression of two putative genes, a zinc transporter (AFLA_072670) and a phytase (AFLA_111040), followed the DIII expression pattern as indicated by the analysis of microarray expression data. qRT-PCR analysis indicated that expression was low in colonized blister, milk, and dough kernels but elevated in dent kernels (Table 6). A putative sugar transporter (AFLA_104900), which was placed into the BI pattern, exhibited a high level of expression in the colonized blister kernels and low in milk, dough, and dent. These results agree with those derived from the analysis of the microarray data.
Characterization of phyl. The putative phytase gene phyl was identified as one of the unique genes associated with colonization of dent kernels. Expression of phyl followed the DIII pattern (Table 5). The gene is located on A. flavus chromosome 3, has an open reading frame of 1,491 bp, and encodes a 497-amino-acid protein. The nucleotide sequence of phyl has high identity with phytases in the genus Aspergillus. In A. oryzae, phyA is $99 \%$ identical to phyl, including the position of a single intron. The proteins encoded by the two genes are $100 \%$ identical.

Mutation of phyl was achieved by gene replacement with the $\arg D$ gene. Of 250 transformants recovered on medium lacking arginine, 25 were screened by PCR and 2 were identified as phyl knockout mutants. The pyrG mutation in one of these strains ( $\Delta$ phylpyr) was complemented and a resulting strain $(\Delta p h y 1)$ was selected for further characterization. The PCR products expected for the replacement of phyl with the $\arg D$ construct koPHY1 are shown in Figure 2. Subsequently, the phyl gene was reintroduced into strain $\Delta$ phylpyr. Transformants were identified by growth on phytate medium and by PCR. One complemented strain (Comp1) was selected for further characterization. PCR analysis of Comp1 indicated the presence of the introduced phyl as well as the original $\Delta$ phyl locus (Fig. 2).

On phosphate control medium, strains AFC-1, Comp1, and $\Delta$ phyl grew equally well (Table 7). However, when grown on

TABLE 5. Patterns of expression for 190 genes identified as differentially expressed in a comparison of colonized, blister, and dent kernels ${ }^{\mathrm{a}}$

\begin{tabular}{|c|c|c|}
\hline Pattern & Description & $\begin{array}{l}\text { Number } \\
\text { of genes }\end{array}$ \\
\hline BI & Upregulated in blister and significantly downregulated in milk. Gene expression may continue to significantly decrease in dough and dent. & 63 \\
\hline BII & $\begin{array}{l}\text { Upregulated in blister, not significantly changed in milk but significantly downregulated in dough. Gene expression may continue to } \\
\text { significantly decrease in dent. }\end{array}$ & 11 \\
\hline BIII & Upregulated in blister, not significantly changed in milk or dough but significantly downregulated in dent. & 46 \\
\hline DI & Downregulated in blister and significantly upregulated in milk. Gene expression may continue to significantly increase in dough and dent. & 9 \\
\hline DII & $\begin{array}{l}\text { Downregulated in blister, not significantly changed in milk but significantly upregulated in dough. Gene expression may continue to } \\
\text { significantly increase in dent. }\end{array}$ & 3 \\
\hline DIII & Downregulated in blister, not significantly changed in milk or dough but significantly upregulated in dent. & 58 \\
\hline
\end{tabular}

a Each gene was evaluated to determine whether significant change in expression occurred in the milk and dough stages.

TABLE 6. Expression analysis by quantitative reverse-transcriptase polymerase chain reaction of Aspergillus flavus genes during colonization of different stages of kernel development ${ }^{\mathrm{a}}$

\begin{tabular}{lccrr}
\hline & \multicolumn{4}{c}{ Relative expression } \\
\cline { 2 - 5 } Gene, function & Blister (R2) & Milk (R3) & Dough (R4) & Dent (R5) \\
\hline AFLA_072670, ZIP transporter & $1.07(1.02-1.12)$ & $2.20(1.78-2.72)$ & $1.00(0.93-1.07)$ & $125.08(105.06-148.91)$ \\
AFLA_104900, sugar transporter & $8.57(7.60-9.67)$ & $2.00(1.42-2.82)$ & $2.70(2.52-2.89)$ & $1.00(0.90-1.11)$ \\
AFLA_111040, phytase & $1.05(0.84-1.31)$ & $1.21(0.96-1.51)$ & $1.00(0.87-1.16)$ & $7.29(6.07-8.76)$ \\
\hline
\end{tabular}

${ }^{a}$ Expression of each gene was normalized to TUB2 and was calculated relative to expression of the kernel stage with the lowest expression. Data represent fold differences in expression. Relative expression of each gene was calculated as $2 \Delta \Delta \mathrm{Ct}$. Range of expression, in parentheses, for each gene $=\left(2^{\Delta \Delta \mathrm{Ct}-\mathrm{s}}-2^{\Delta \Delta \mathrm{Ct}+\mathrm{s}}\right)$, where $\mathrm{s}=$ the standard deviation of the $\Delta \Delta \mathrm{Ct}$ value. For each developmental stage, three biological replicates were analyzed.

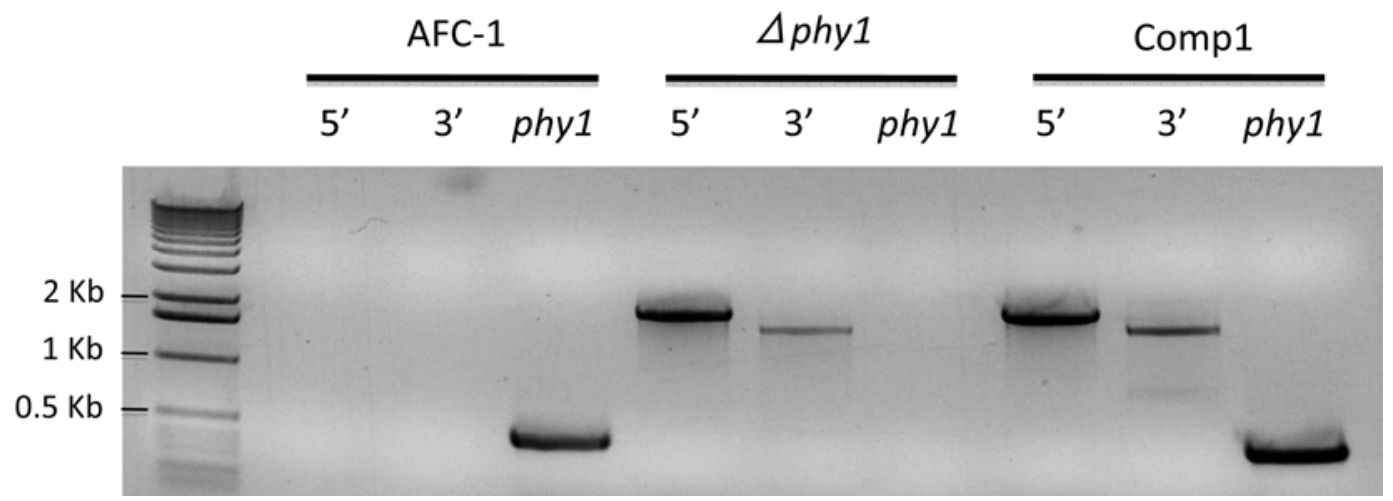

Fig. 2. Polymerase chain reaction analysis of Aspergillus flavus strains AFC-1, $\Delta p h y 1$, and Comp1. Genomic DNA from each strain was used as template. A 1,253 -bp band $\left(5^{\prime}\right)$ and 1,132-bp band ( $\left.3^{\prime}\right)$ indicate the presence of the disruption construct koPhyl at the phyl locus. The presence of a 495 -bp band (phyl) indicates the presence of the phyl gene. The first lane contains a 1-kb DNA ladder. 
phytate medium, which contained sodium phytate as the phosphorus source, growth of $\Delta p h y l$ was reduced to 30 to $40 \%$ that of AFC-1 and Comp1 (Table 7). Phytase activity in culture filtrates from strains AFC-1 and Comp1 released $0.85( \pm 0.07)$ and 0.82 $( \pm 0.07) \mu \mathrm{mol}$ of phosphate, respectively, from sodium phytate after $24 \mathrm{~h}$ of incubation. In contrast, strain $\Delta p h y 1$ released 0.49 $( \pm 0.06) \mu \mathrm{mol}$.

Pathogenicity was tested by inoculation of kernels through a wound of maize ears. Five days after inoculation, growth of $\Delta p h y 1$ at the surface of the wound site was less than on ears inoculated with AFC-1 and Comp1 (Fig. 3). Ergosterol analysis indicated that growth of $\Delta p h y l$ was $<25 \%$ that of AFC-1 and Comp1 (Table $8)$. Although aflatoxin concentrations were less in kernels inoculated with $\Delta p h y l$, the amount of aflatoxin relative to ergosterol content was not significantly different among strains (Table 8).

\section{DISCUSSION}

The goal of this research was to characterize the molecular response in A. flavus during colonization of maize kernels at different development stages (R2 to R5). This was accomplished by the analysis of genome-wide expression data obtained from microarrays. RNA for analysis was obtained from living kernels that were removed from ears, wounded, and placed into vials prior to inoculation. Under these conditions, A. flavus grew equally well on all four kernel development stages. Published studies have shown that, under field conditions, A. flavus is present on silks and can infect maize kernels in early stages of development $(6,13,20,27)$. Conditions in the vials simulate field conditions associated with insect damage, which can facilitate the infection process (13).

TABLE 7. Growth of Aspergillus flavus strains AFC-1, Aphy1, and Comp1 on phytate and phosphate $\left(+\mathrm{PO}_{4}\right)$ control media and phytase activity ${ }^{\mathrm{a}}$

\begin{tabular}{|c|c|c|c|}
\hline & \multicolumn{2}{|c|}{ Growth $^{\mathrm{b}}$} & \multirow[b]{2}{*}{ Phytase $^{c}$} \\
\hline & $+\mathrm{PO}_{4}$ & Phytate & \\
\hline AFC-1 & $75(3.5)$ & $30(2.3) *$ & $0.85(0.06)$ \\
\hline$\Delta p h y l$ & $75(7.1)$ & $10(3.1)^{*}$ & $0.49(0.06)^{*}$ \\
\hline Comp1 & $75(7.0)$ & $24(2.1)^{*}$ & $0.82(0.07)$ \\
\hline
\end{tabular}

a Values inside the parentheses are standard error; $*$ indicates significant difference from other values in column. Data were analyzed by an analysis of variance with a Fisher's least significant difference test to compare means ( $\alpha=0.05$ ) (PROC GLM; SAS Institute 2001).

${ }^{b}$ Values are mean milligrams of dry weight of three replicates measured after 5 days of incubation.

${ }^{c}$ Micromoles of phosphate released from sodium phytate after $24 \mathrm{~h}$ of incubation. Values are mean from three replicates.

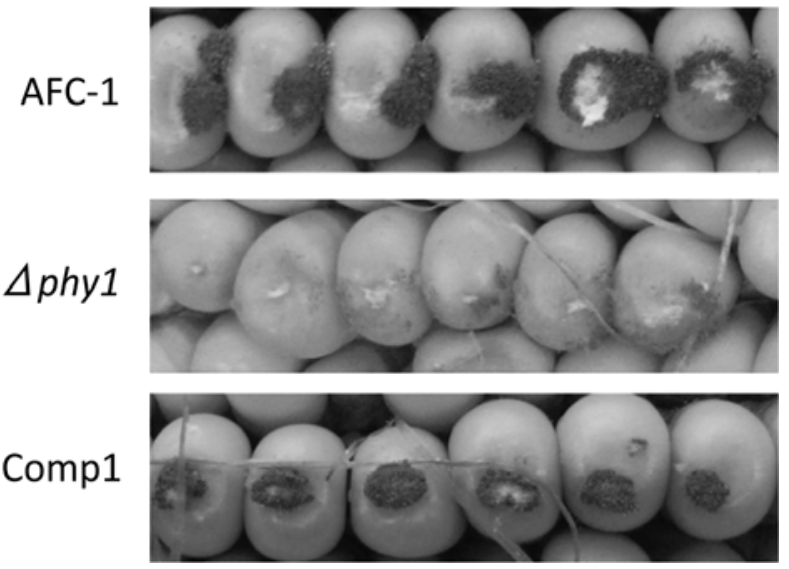

Fig. 3. Symptoms of maize kernels wound inoculated with conidia from Aspergillus flavus strains AFC-1, $\Delta$ phyl, and Comp1. Pictures were taken at 5 days after inoculation.
Maize kernel development is a transient process, which provides a changing nutrient environment for the pathogen. Our microarray analysis revealed significant differences in gene expression between the colonized kernel stages. In a study of metabolite changes, Ingle et al. (14) recognized two phases in developing kernels. They describe the first, up to 28 DAP, as a phase during which soluble sugars and amino acids accumulate. Wang and Larkins (35) also noted that the level of free amino acids is highest in the early stages of development. The set of upregulated genes detected in colonized blister (R2) kernels reflects the nutrients available to A. flavus during colonization of these newly developing kernels. Among these genes were four putative amino acid transporters and one sugar transporter. By 28 DAP, the second phase of kernel development, there is a substantial increase in protein synthesis and polysaccharide accumulation (14). Based on their description of kernel development, 28 DAP would correspond to the R4 (dough) stage (Richie et al. 2005). Distinct differences in the expression of 772 genes were detected in A. flavus when grown on R4 and R5 kernels. There were 113 genes identified as unique to growth on dent (R5) kernels, including putative lipases and zinc transporters among the upregulated genes; and amino acid transporters, pectin metabolism, and sugar transporters among the downregulated genes. These results indicate that the kernel environment in dent is a major change point in development of the kernels as experienced by A. flavus.

The significance of the change in kernel environment was best illustrated by our analysis of the 225 genes identified in the comparison between blister and dent kernels. Eighty-four percent of these genes could be assigned to one of six patterns of change from blister to dent. Fifty-five percent of these genes followed the two patterns (BIII and DIII) in which the significant change in expression occurred between dough and dent. Included in the group with higher expression during growth on blister, milk, and dough kernels (when compared with dent kernels) were genes involved in carbohydrate metabolism, sugar transport, and amino acid transport. The expression of these genes indicates that, when A. flavus encounters the nutrients in young kernels, which Ingle et al (14) described as phase 1 kernels, the fungus expresses a set of genes specific for acquiring these abundant nutrients. During growth on dent kernels, these nutrients are less available; thus, expression of the genes is significantly reduced. Included in the 58 genes following the DIII pattern of expression, which were upregulated during growth on dent kernels, were putative genes involved in lipid catabolism, zinc acquisition, and aflatoxin production. These results are indicative of the impact that the change in kernel composition has on A. flavus.

The significant expression of putative zinc transporters and aflatoxin biosynthesis genes is intriguing. The absence of zinc is inhibitory, while increasing zinc levels promotes growth and increases aflatoxin production in $A$. parasiticus $(9,21)$. Lillehoj et

TABLE 8. Growth and aflatoxin production on wounded inoculated maize ears $^{\mathrm{a}}$

\begin{tabular}{lcc}
\hline Strain & Growth $^{\mathrm{b}}$ & Aflatoxin $^{\mathrm{c}}$ \\
\hline AFC-1 & $56.2(13.1)$ & $1.4(0.7)$ \\
$\Delta$ phy1 & $12.1(6.6)^{*}$ & $2.3(0.6)$ \\
Comp1 & $57.7(11.7)$ & $2.2(0.6)$ \\
\hline
\end{tabular}

a Ears were inoculated by a pin bar dipped into a suspension of $1 \times 10^{7}$ conidia/ml. Disease was evaluated 5 days after inoculation. Values inside the parentheses are standard error.

b Values are mean micrograms of ergosterol per gram of maize kernel of three replicates; * indicates significant difference from other values in column. Data were analyzed by an analysis of variance with a Fisher's least significant difference test to compare means $(\alpha=0.05)$ (PROC GLM; SAS Institute 2001)

c Values are mean micrograms of aflatoxin B1 per microgram of ergosterol per gram of maize kernel of three replicates. 
al. (18) showed that the addition of zinc to defatted maize kernels increased aflatoxin production in A. flavus. Also, zinc availability was shown to correlate with the expression of omtA, an aflatoxin biosynthesis gene (4). In our analysis, five of the six zinc-related genes with high expression during growth on dent kernels were classified as putative ZIP proteins based on the presence of signature amino acid sequences (8). ZIP transporters, which are similar to Zrt1 in yeast and Irt1 in Arabidopsis, are a primary means of zinc acquisition; however, each individual transporter has a different affinity for zinc (10). Zinc and other cations are sequestered in seed by phytate (23). At maturity, the maize germ contains 88 and $68 \%$ of the total phytate and zinc, respectively (23). A zinc-limiting environment would promote the expression of ZIP transporters $(34,41)$, which is consistent with the expression of the five genes identified in our analysis.

One mechanism used by microbes to acquire the phosphorus in phytate and the associated cations, such as zinc, is to produce an extracellular phytase (33). Oboh et al. (22) reported that $A$. flavus responded to the presence of phytate in cassava flour by producing phytase. Our analysis of A. flavus indicated that a phytase gene was upregulated during growth on dent kernels, suggesting that the pathogen was responding to higher phytate levels in the germ of these kernels. No previous publications have described the role of phytase activity during pathogenesis. Our results suggest that phyl is required for phosphate acquisition when phytic acid is the primary source and that the gene impacts pathogenesis on maize kernels. Colonization of kernels by a strain lacking a functional phyl was significantly reduced, indicating that phytate is a major source of phosphorus for the fungus within the kernel environment. Although total aflatoxin production by $\Delta p h y l$ was reduced in the infected kernels, the amount relative to growth (ergosterol content) was no different than the wild-type strain. These results imply that phytase activity is important in $A$. flavus colonization of maize kernel but the enzyme does not impact aflatoxin biosynthesis. We can only speculate as to why aflatoxin biosynthesis was not affected in the $\Delta p h y l$ strain. The results suggest that, if zinc is critical for aflatoxin production, the mutant could acquire sufficient amounts of the mineral. The possibility exist that one or more other phytases are expressed and provide the mutant with zinc. Although only one phytase gene in the related fungus $A$. oryzae has been described (32), two forms of the enzyme have been characterized (7). A search of the annotated genome of $A$. flavus revealed three other genes that have been designated as putative phytases (AFLA089400, AFLA117760, and AFLA019800). The nucleotide sequences of these genes have no significant similarity to phyl and the similarity at the amino acid level is low. Also, the expression of these genes were not significantly different in our microarray analysis. It is possible that phosphatase activity from one of these enzymes is degrading phytate, although not efficiently. Such activity could explain the slow growth of the mutant observed in kernels and phytate medium as well as the low level of phosphate released in the phytase assays.

In conclusion, this study provides evidence that gene expression in A. flavus responds to the changing environment within a developing maize kernel. Colonization of each development stage is marked by a unique set of genes expressed by the pathogen during colonization, consistent with what is known about nutrient composition at each developmental stage. The study also provides evidence that phytase has a role in pathogenicity but not in aflatoxin production. The requirement of phytase for colonization of kernels after 28 DAP is consistent with observations that infection increases as the kernels approach maturity (24).

\section{ACKNOWLEDGMENTS}

Support for this research was provided by USDA/NRICGP, award number 2006-35604-16666. We thank L. Dunkle for his helpful discussions and review of this manuscript; and G. O'Brian, A. Dolezal, and M. McDonough for their assistance.

\section{LITERATURE CITED}

1. Bluhm, B. H., Kim, H., Butchko, R. A., and Woloshuk, C. P. 2008. Involvement of ZFR1 of Fusarium verticillioides in kernel colonization and the regulation of FST1, a putative sugar transporter gene required for fumonisin biosynthesis on maize kernels. Mol. Plant Pathol. 9:203-211.

2. Bluhm, B. H., and Woloshuk, C. P. 2005. Amylopectin induces fumonisin B1production by Fusarium verticillioides during colonization of maize kernels. Mol. Plant-Microbe Interact. 18:1333-1339.

3. Cotty, P. J. 1989. Virulence and cultural characteristics of two Aspergillus flavus strains pathogenic on cotton. Phytopathology 79:808-814.

4. Cuero, R. M, Ouellet, T., Yu, J., and Mogongwa, N. 2003. Metal ion enhancement of fungal growth, gene expression and aflatoxin synthesis in Aspergillus flavus: RT-PCR characterization. J. Appl. Microbiol. 94:953961.

5. Davis, N. D., Diener, U. L., and Agnihotri, V. P. 1967. Production of aflatoxins $B_{1}$ and $G_{1}$ in chemically defined medium. Mycopathologia 31:251-256.

6. Diener, U. L., Cole, R. J., Sanders, T. H., Payne, G. A., Lee, L. S., and Klich, M. A. 1987. Epidemiology of aflatoxin formation by Aspergillus flavus. Annu. Rev. Phytopathol. 25:249-270.

7. Fujita, J., Seiko Shigeta, S., Yamane, Y., Fukuda, H. Kizaki, Y., Wakabayashi, S., and Ono. K. 2003. Production of two types of phytase from Aspergillus oryzae during industrial Koji making. J. Biosci. Bioeng. 95:460-465.

8. Guerinot, M. L. 2000. Review: The ZIP family of metal transporters. Biochim. Biophys. Acta 1495:190-198.

9. Gupta, S. K., Maggon, K. K., and Venkitasubramanian, T. A. 1976. Effect of zinc on adenine nucleotide pools in relation to aflatoxin biosynthesis in Aspergillus parasiticus. Appl. Environ. Microbiol. 32:753-756.

10. Hall, B. P., and Guerinot, M. L. 2006. The role of ZIP family members in iron transport. Pages 311-326 in: Iron Nutrition in Plants and Rhizospheric Microorganisms. L. L. Barton and J. Abadia, eds. Springer, The Netherlands.

11. He, Z., Price, M. S., O'Brian, G. R., Georgianna, D. R., and Payne, G. A. 2007. Improved protocols for the functional analysis in the pathogenic fungus Aspergillus flavus. BMC Microbiol. 26:7-104.

12. Heinonen, J. K., and Lahti, R. J. 1981. A new and convenient colorimetric determination of inorganic orthophosphate and its application to the assay of inorganic pyrophosphatase. Anal. Biochem. 113:313-317.

13. Hill, R. A., Wison, D. M., McMillian, W. W., Widstrom, N. W., Cole, R. J., Sanders, T. H., and Blankenship, P. D. 1985. Ecology of the Aspergillus flavus group and aflatoxin formation in maize and groundnut. Pages 79-96 in: Trichothecenes and Other Mycotoxins. J. Lacey, ed. John Wiley \& Sons, New York.

14. Ingle, J., Beitz, D., and Hageman, R. H. 1965. Changes in composition and maturation of maize seeds. Plant Physiol. 40:835-839.

15. Keller, N. P., Butchko, R. A., Sarr, B., and Phillips, T. D. 1994. Visual pattern of mycotoxin production in maize kernels by Aspergillus spp. Phytopathology 84:483-488.

16. King, S. B., and Scott, G. E. 1982 Field inoculation techniques to evaluate maize for reaction to kernel infection by Aspergillus flavus. Phytopathology 72:782-785.

17. Li, C., and Wong, W. H. 2001. Model-based analysis of oligonucleotide arrays: Expression index computation and outlier detection. Proc. Natl. Acad. Sci. USA 98:31-36.

18. Lillehoj, E. B., Garcia, W. J., and Lambrow, M. 1974. Aspergillus flavus infection and aflatoxin production in corn: Influence of trace elements. Appl. Microbiol. 28:763-767.

19. Liu, Y., and Wu, F. 2010. Global burden of aflatoxin-induced hepatocellular carcinoma: A risk assessment. Environ. Health Perspect. 118:818-824.

20. Marsh, S., and Payne, G. A. 1984. Scanning EM studies on the colonization of dent corn by Aspergillus flavus. Phytopathology 74:557-561.

21. Niehause, W. G., and Dilts, R. P. 1982. Purification and characterization of mannitol deydrogenase from Aspergillus parasiticus. J. Bacteriol. 151:243-250.

22. Oboh, G., Akindahunsi, A. A., and Oshodi, A. A. 2003. Dynamics of phytate-zinc balance of fungi fermented cassava products (flour and gari). Plant Food Hum. Nutr. 58:1-7.

23. O'Dell, B. L., De Boland, A. R., and Koirtyohann, S. R. 1972. Distribution of phytate and nutritionally important elements among the morphological components of cereal grains. J. Agric. Food Chem. 20:718-723.

24. Payne, G. A. 1998. Process of contamination by aflatoxin producing fungi and their impacts on crops. Pages 278-306 in: Mycotoxins in Agriculture and Food Safety. K. K. Sinha and D. Bhatnagar, eds. Marcel Dekker, Inc., New York. 
25. Payne, G. A., Yu, J., Nierman, W. C., Machida, M., Bhatnager, D., Cleveland, T. E., and Dean, R. A. 2008. A first glance into the genomic sequence of Aspergillus flavus. Pages 15-23 in: The Aspergilli: Genomics, Medical Aspects, Biotechnology, and Research Methods. G. H. Goldman and S. A. Osmani, eds. CRC Press, Boca Raton, FL.

26. Probst, C., Njapau, H., and Cotty, P. J. 2007. Outbreak of an acute aflatoxicosis in Kenya 2004: Identification of the casual agent. Appl. Environ. Microbiol. 73:2762-2764.

27. Rambo, G. W., Tuite, J., and Crane, P. 1974. Preharvest inoculation and infection of dent corn ears with Aspergillus flavus and A. parasiticus. Phytopathology 64:797-800.

28. Ritchie, S. W., Hanway, J. J., and Benson, G. O. 1993. How a corn plant develops. Iowa State Univ. Spec. Rep. No. 48.

29. Smith, C. A., Robertson, D., Yates, B., Nielson, D. M., Brown, D., Dean, R. A., and Payne, G. A. 2008. The effect of temperature on natural antisense transcript (NAT) expression in Aspergillus flavus. Curr. Genet. 54:241-269.

30. Suanthie, Y., Cousin, M. B., and Woloshuk, C. P. 2009. Multiplex realtime PCR for detection and quantification of mycotoxigenic Aspergillus, Penicillium, and Fusarium. J. Stored Prod. Res. 45:139-145.

31. Thapar, G. S. 1988. Metabolic behavior of aflatoxin producing strain and non-toxigenic strain of Aspergillus flavus to different sources of nitrogen and glucose concentration. Mycopathologia 102:9-12.

32. Uchida, H., Arakida, S., Sakamoto, T., and Kawasaki, H. 2006. Expression of Aspergillus oryzae phytase gene in Aspergillus oryzae RIB40 niaD. J. Biosci. Bioeng. 102:564-567.

33. Vats, P., and Banerjee, U. C. 2004. Production studies and catalytic properties of phytases (myo-inositolhexakisphosphate phosphohydrolases): An overview. Enzyme Microbiol. Technol. 35:3-14.

34. Vicentefranqueira, R., Moreno, M. A., Leal, F., and Calera, J. A. 2005. The zrfA and $z r f B$ gene of Aspergillus fumigatus endcode the zinc transporter proteins of a zinc uptake system induced in an acid, zincdepleted environment. Eukaryot. Cell 4:337-848.

35. Wang, X., and Larkins, B. A. 2001. Genetic analysis of amino acid accumulation in opaque-2 maize endosperm. Plant Physiol. 125:17661777.

36. Woloshuk, C. P., Seip, E. R., Payne, G. A., and Adkins, C. R. 1989. Genetic transformation system for the aflatoxin-producing fungus Aspergillus flavus. Appl. Environ. Microbiol. 55:86-90.

37. Wotton, H., and Strange, R. N. 1987. Increased susceptibility and reduced phytoalexin accumulation in drought-stressed peanut kernels challenged with Aspergillus flavus. Appl. Environ. Microbiol. 53:270-273.

38. Young, T. E., and Gallie, D. R. 2000. Regulation of programmed cell death in maize endosperm by abscisic acid. Plant Mol. Biol. 42:397-414.

39. Young, T. E., Gallie, D. R., and DeMason, D. A. 1997. Ethylene-mediated programmed cell death during maize endosperm development of wildtype and shrunken2 genotypes. Plant Physiol. 115:737-751.

40. Yu, J., Chang, P., Ehrlich, K. C., Cary, J. W., Bhatnagar, D., Cleveland, T. E., Payne, G. A., Linz, J. E., Woloshuk, C. P., and Bennett, J. W. 2004. Clustered pathway genes in aflatoxin biosynthesis. Appl. Environ. Microbiol. 70:1253-1262.

41. Zhao, H., and Eide, D. J. 1997. Zap1p, a metalloregulatory protein involved in zinc-responsive transcriptional regulation in Saccharomyces cerevisiae. Mol. Cell. Biol. 17:5044-5052. 